\title{
A Need to Re-integrate Prisoners to the Community: A Case of Polokwane Medium B Prison, South Africa
}

\author{
By Michael N. Khwela*
}

There seems to be a lack of communication between communities and the Department of Correctional Services (DCS) when exoffenders are re-integrated to the communities (Zondi 2012). The international approach that the South African government subscribe to, perceive rehabilitation as ensuring that imprisoned offenders are treated with care and dignity such that their re-entry to society should not be a challenge (Cilliers \& Smit 2007; Singh 2008). There is still no difference between rehabilitation and incarceration in South Africa due to the correctional environment. The rate of incarceration has increased dramatically where prisons are filled to capacity with an alarming overcrowding that leads to bad environments for the offenders. Crime continues inside the prison walls and gangs are rife behind bars (Singh 2008). The available data on recidivism is an indication that the ex-offenders that are released by the DCS are not rehabilitated (Freeman 2003). However, the move by the democratically elected South African government from the Department of Prisons to the Department of Correctional Services designates that the intention was to move from mere incarceration to corrections and rehabilitation of offenders (Cheliotis 2008). But this correctional objective seems to be defeated if a corrected inmate gets back to join a family that is already dysfunctional, and hence involuntarily the corrected inmate reverts back to his/her offence. The DCS (2005) compatibly tries to address the issue of rehabilitation and re-entry of offenders to their communities including the importance of the family in the rehabilitation of offenders. Nonetheless, if offenders are returning to neighbourhoods that do not provide access to the sort of services that are important for re-integrating ex-offenders into the broader community; it stands to reason that the ex-offenders will be less likely to succeed in the post-release transition and more likely to recidivate. Consequently, the rehabilitation of an incarcerated inmate with the exclusion of the family could be an incomplete process. Hence this paper seeks to ascertain the characteristics and determinants of recidivism.

${ }^{*}$ Lecturer, University of Limpopo, South Africa. 


\section{Introduction}

The crime rate in South Africa is at an extreme level (Strydom, 2009) and the prison population is as well increasing at an alarming rate due to the precipitous incarceration rate in the country when compared to international trends (Singh, 2008). The households of the incarcerated prisoners who are breadwinners are assumed to be in household poverty trap as there is no income being generated during the period of incarceration. When a member of the family is incarcerated, more especially when it is the breadwinner, the family is in most cases faced with income problems due to the cost of living, which exposes them to poverty and ultimately crime (Seymour \& Hairston, 2001; Travis \& Waul, 2003; Strydom, 2009; Eddy \& Poelhmann, 2010). According to Strydom (2009); incarceration affects not only the prisoner but also the family.

Some researchers argue that incarceration might be regarded as bringing relief to families from the challenges of an active offender. However, it also brings about new costs associated with the taking care of the incarcerated family member like money for collect telephone calls and commissary (Fishman 1990; Braman 2004; Travis, McBride \& Solomon, 2005). If the offender was providing an income to the household prior to incarceration, the family would struggle to compensate for this loss. In most cases, prisoners' families have to adjust economically when a family member is incarcerated (Christian, Mellow \& Thomas, 2006). Research on how incarceration impacts on prisoners' families has shown that families that try to maintain the relationship with the offender, mostly end-up failing to keep-up due to financial implications (Fishman, 1990; Hagan \& Dinovitzer, 1999; Braman, 2004; Arditti, 2005; Christian et al., 2006; Eddy \& Poelhmann, 2010).

During January 1995, South Africa had 443 prisoners serving life sentences, and by January 2005 the number had increased to 5,745, which is 1,296 percent increase in a period of ten years, which led to the overcrowding in the prison population (Mujuzi, 2008). The Department of Correctional Services (DCS) in South Africa accommodates more than 160000 inmates with an average of $150 \%$ overcrowding after achieving democracy in 1994 (Mujuzi, 2008). The International Centre for Prison Studies indicates that at 30 April 2012, 307 out of 100000 South Africans were in prison, based on an estimated national population of 51.08 million and placing it the 28th out of 216 countries in relation to their rates of incarceration (ICPS, 2012).

In light of the over-crowding in the prisons and the rapid increase in the number of prisoners due to recidivism and other common crimes, there is a need to reintegrate prisoners to the community (Cheliotis, 2008). The DCS has proper policies with regard to rehabilitation of inmates but there is not much with regard to the families of incarcerated inmates in breaking the cycle of poverty and crime. Consequently, the rehabilitation of an incarcerated inmate with the exclusion of the family might be an incomplete process as family involvement is central to successful offender re-entry (Cheliotis, 2008; Gibson et al., 2009). The families left behind after the incarceration of the breadwinner 
are vulnerable in such a way that the family dynamics are compelled to change so as the family structure. Additionally, the released offenders may be regarded as bringing back crime to the neighbourhood such that it is less safe but the return reunites the families although most families are by then dysfunctional (Travis et al., 2005). There is also a challenge to the offender re-entry by the non-criminal neighbours who make it very difficult for offenders to join the community. These non-criminal neighbours are often wary of the offenders and which in most of the times make it difficult for the returning offender to find meaningful employment (Gibson et al., 2009).

If offenders are returning to neighbourhoods that do not provide access to the sort of services that are important for re-integrating them into the broader community, it stands to reason that they will be less likely to succeed in their post-release transition and more likely to recidivate (Travis et al., 2005). It is assumed that a better option for dealing with crime is to place greater effort on the rehabilitation of offenders, in particular, programs that adhere to the reduction of offender recidivism. The White Paper on Corrections in South Africa is based on the South African Constitution (RSA, 1996), which has a provision of a detention system that is based on a Bill of Rights that provides the premise within which the DCS should handle incarcerated inmates (Cilliers \& Smit, 2007; Singh, 2008). Consequently, there is a need to compare and contrast the prison models in South Africa which are incarceration and rehabilitation to reduce recidivism and the ensnarement of prisoners' families to poverty and crime.

This paper sets out to explore the prison models in South Africa which are incarceration and rehabilitation with regard to the ensnarement of prisoners' families to poverty and crime; hence this paper intends to fill this gap in literature. This paper is presented in six sections, including the introduction. Section two theorises the impact of incarceration on recidivism; section three deals with the poverty theory; followed by the discussion on the need to reintegrate ex-offenders to the community in section four; section five analyses the incarceration and rehabilitation models; and, a conclusion is provided in section six. To this extent, the study seeks to investigate the role of incarceration and rehabilitation in the ensnarement of prisoners' families to poverty and crime.

\section{Incarceration and Recidivism}

In ancient times, a behaviour that was meted to be abnormal in society was dealt with by the immediate community. Prisons are not indigenous to Africa but a Western tool that was used to rehabilitate an offenders' behaviour to a law-abiding citizen. Incarceration came about in South Africa when it was introduced by the Dutch colonists after the British had come-up with the penal policy. During the 1840s the prisoners were used to work on public projects. The De Beers mining company introduced the first private prisons in South 
Africa. The majority of prisoners were those who had violated pass laws (DCS, 2009). Incarceration means to be confined in prison (confinement) or jailed. Confinement, whether before or after criminal conviction is called incarceration. A jail is a facility built to incarcerate offenders before or after the trial.

The rate of incarceration has increased dramatically where prisons are filled to capacity with an alarming overcrowding that leads to bad environments for the offenders. According to Singh (2008), crime continues inside the prison walls and gangs are rife behind bars. The available data on recidivism is an indication that the ex-offenders that are released by the DCS are not rehabilitated (Freeman, 2003). Most of these ex-offenders they reoffend within a period of three years after they had been released up until they are in mid-forties where the rate of re-arrest falls noticeably (Freeman, 2003). Due to the high rate of crime and incarceration together with the alarming data on recidivism; Freeman (2003), states that, almost any programme that reduces recidivism would pass social cost-benefit tests.

Incarceration entails imprisonment or confinement as a deterrent without associating any privileges to it while rehabilitation of offenders may imply a more cooperative and remedial approach (Singh, 2008). The DCS (2005), states that rehabilitation should include the correction of the offending behaviour and is achieved through interventions to change attitudes, behaviour and social circumstances. However, what is said by the DCS compared to what is experienced by the offenders within prison are very much inconsistent (Singh, 2008). The international approach that the South African government subscribe to, perceive rehabilitation as ensuring that imprisoned offenders are treated with care and dignity such that their re-entry to society should not be a challenge (Cilliers \& Smit, 2007; Singh, 2008). According to Singh (2008), there is still no difference between rehabilitation and incarceration in South Africa due to the correctional environment.

The move by the democratically elected South African government from the Department of Prisons to the Department of Correctional Services indicates that the intention was to move from mere incarceration to corrections and rehabilitation of offenders (Cheliotis, 2008). But this correctional objective seems to be defeated if a corrected inmate gets back to join a family that is already dysfunctional, and hence involuntarily the corrected inmate reverts back to his/her offence. The DCS (2005) compatibly tries to address the issue of rehabilitation and re-entry of offenders to their communities including the importance of the family in the rehabilitation of offenders. Family involvement is also central to successful offender re-entry. If offenders are returning to neighbourhoods that do not provide access to the sort of services that are important for re-integrating them into the broader community, it stands to reason that they will be less likely to succeed in their post-release transition and more likely to recidivate (Travis et al., 2005).

Recidivism is the other momentous challenge which is usually not taken acutely, which is presently estimated at between $80-90 \%$ (Pelser \& Rauch, 2001). Consequently, the rehabilitation of an incarcerated inmate with the 
exclusion of the family could be an incomplete process. Literature proposes that a combination of family, community and societal conditions, especially poverty collude to trap offenders and their families into a cycle of crime (Cheliotis, 2008). Thus far, little or no attention has been focused on the working together of social services, criminal justice system, health care providers and communities to meet the needs of families left behind (Travis et al., 2005). According to Zondi (2012), there is a lack of communication between communities and the DCS when ex-offenders are re-integrated to the communities.

The rate of awaiting trial prisoners is high due to the non-finalisation of investigations by SAPS (Pelser \& Rauch 2001). These awaiting trial prisoners have to be kept by the Department of Correctional Services, which adds to the present challenge of overpopulation in prison. Some awaiting trial prisoners have been in prison for more than five years (Singh, 2008).

The DCS expects the family to play a role in the correction of offenders; however, nobody has shown interest in the families of incarcerated offenders (Arditti, 2005; Zondi, 2012). The responsibility of the DCS is to correct behaviour, in a secure, safe and humane environment to facilitate the achievement of rehabilitation and the avoidance of recidivism (Singh, 2008). The removal of a parent due to incarceration might be beneficial or detrimental to the child but more often are a traumatic life event that intensifies the problems that the involved children are already facing (Hagan \& Dinovitzer, 1999). Hagan \& Dinovitzer (1999) further states that the associated sociological and criminological theories distinguish three fundamental effects of parental incarceration on the children. These fundamental effects include economic deprivation, loss of parental socialisation, and the stigma of shame of societal labelling (Hagan \& Dinovitzer, 1999). According to Kennedy \& Chance (2011), the penal system is hurting the people that it is supposed to protect with the mass incarcerations that are happening. The mass incarcerations also disrupt family ties, increases poverty and ultimately crime, which logically will have a serious negative impact to the children (Kennedy \& Chance, 2011).

\section{Incarceration/Rehabilitation \& Ensnarement of Prisoners' Families to Poverty}

Poverty is defined as the deprivation of survival necessities. Poverty reduction is the key objective of development such that the Millennium Development Goals target halving world poverty by 2015. Poverty is regarded as a situation where there is a severe deprivation of basic human needs, which includes: food, healthy drinking water, sanitation facilities, shelter, education and information (Statsa, 2005). The other definition of poverty is based on failure to the basic human needs which not only include food, clothing and dwelling, but also health and education (Sen, 1999). In conceptualising 
poverty, there are two terms that are used to define poverty, which are relative poverty and absolute poverty.

Absolute poverty used to be regarded as primary poverty until in 1995 in Copenhagen during the World Summit for Social Development. The concept absolute poverty refers to poverty that exists independently of any reference group and it becomes synonymous with subsistence poverty according to Noble, Ratcliffe \& Wright (2004). A family is referred to be poor when it is unable to attain things necessary for its survival. This could mean that the family generates insufficient total earning to obtain minimum necessities. The World Bank calculates that a fourth of the world population in the developing world, which is about 1.2 billion people are living in poverty that is below $\$ 1$ a day (World Bank, 2000).

However, the advocates of relative poverty criticise heavily this absolute notion of poverty (Noble et al., 2004). Other scholars also argue that the mere inadequate income does not adequately describe poverty. The recent definition of poverty is based on the lack of opportunities. This definition means that poverty does not only mean the lack of adequate income and basic human needs, but the tacit denial of opportunities pushes them into unemployment resulting in loss of income and finally inability to meet the basic needs (Sen, 1999). The relative poverty approach makes it very difficult as to where to draw the line in contrast to absolute poverty. The academics over the course of the twentieth century became aware of the limitations of absolute concepts and subsistence definitions of poverty. Relative poverty actually means that individuals, families and groups in the population are said to be in poverty when they lack resources that other families or groups in the same population are able to achieve. According to Sen (1983), the notion of relative poverty might mean that some groups of people will always be poor juxtaposed to others as there will never be absolute equality.

In the monetary approach also known as the utilitarian approach, poverty is the deprivation of utility income, which in principle includes all income in money metric. This approach is usually measured by consumption versus income and the poverty line is relative or nutrition based. Measuring poverty in this approach is attributed to individuals but measured by family per consumption. According to Sen (1993), the utilitarian approach of poverty is ethically flawed as it neglects to consider the physical condition of life of the observed object. The other challenges with this approach are that it does not consider group conditions, causes of poverty and it neglects social goods. In the capability approach to development, the objective is to enhance the individual's capabilities to be or do different things (Sen, 1979, 1993, 2009; Nussbaum 2000).

Poverty is regarded as the failure of some basic capability to function. The first question with regard to capability approach is finding out what are the basic capabilities? Some scholars have attempted to define them with education and health being mentioned but there is an overlapping consensus. This is an economic theory that was conceived by the 1980's as a welfare economics approach with the core focus on what individuals are able to do. According to 
Nussbaum (2000), there are ten central capabilities that are supposed to be supported by all democracies. Consequently, Sen and Nussbaum offer a capability-based critique of using the Gross Domestic Product (GDP) and Gross National Product (GNP) as measures of well-being.

\section{A Need to Re-Integrate Ex-Offenders to the Community}

The most detrimental collateral consequence of incarceration is the separation of the parent to the children and exacerbated when the parent and the child lack regular contact (Genty, 2002). Genty (2002), further states that, the limited contact between the incarcerated parent and their children has a damaging impact on the parent-child relationship. Mostly, when parents go to prison, it is usually for a lengthy period of time without having contacts with their children and being incarcerated very far from home (Mumola, 2000; Seymour \& Hairston, 2001; Genty, 2002). The challenge is that prisoners' families and the effects of imprisonment on families and children are neglected in academic research, public policy and media coverage (Hagan \& Dinovitzer, 1999; Murray, n.d.). It therefore stands to reason that if we do not attend to the effects of imprisonment on children, we might be punishing innocent victims and ultimately possibly causing crime in the next generation (Murray, n.d.).

Dysfunctional families provide fertile ground for acts of criminality. Also lack of employment, public infrastructure, social recreational infrastructure and poverty combined with dysfunctional families put the youth at risk. Research has shown that children whose lives are impacted by traumatic family environments (e.g., parental neglect, abuse, and addiction), as well as by the severe disruption associated with the imprisonment of a parent, are disproportionately prone to become delinquent as adolescents or as young adults (Seymour \& Hairston, 2001; Travis \& Waul, 2003; Strydom, 2009). Control and socialisation theories consider early adolescence as a period when there are significant struggles between allegiances to family and peers in which the absence of a parent may well shift the balance of these struggles in the favour of antisocial peers. Because of their increased vulnerability to the development of deviant activity, these children are particularly in need of preventive interventions.

A substantial number of families that are left behind were at risk before the family member was incarcerated and it becomes worse when the member is back. It is only a minority of such families who become better when a breadwinner is incarcerated. According to Arditti (2005), at least 10 million children have a parent involved in the CJS and a substantial amount of incarcerated women and men have a child (Seymour \& Hairston, 2001; Travis \& Waul, 2003; Strydom, 2009). Although the data is minimal on the families left behind, documents have started to indicate the impact that incarceration has on children of incarcerated parents like poor educational performance, drug 
abuse and the involvement of the children themselves with the CJS (Arditti, 2005).

Literature proposes that a combination of family, community and societal conditions, especially poverty collude to trap offenders and their families into a cycle of crime (Cheliotis, 2008). The perception among communities is that incarceration reduces crime while data indicates that incarceration amounts to a mere 25\% crime reduction (Murray, n.d.). Doubling incarceration rates would double the costs of incarceration together with the social costs of the affected families (Travis et al., 2005). The lengthy sentences that are imposed have an impact on the offenders' children as the children may be poorly educated or socially alienated and more likely to be involved in crime. According to Singh (2008), incarcerated inmates are exposed to the teachings of crime behind bars as there are gangs that are controlling the inmates.

The Republic of South Africa criminal justice system is implicit not to be anxious about the children of the incarcerated parents but ponders mostly on prisoners themselves as attested by the available literature (Fishman, 1990; Travis et al., 2005; Strydom, 2009). To this extent, research has just been focusing on the rehabilitation of prisoners and not much about the families' ensnarement to crime (Arditti, 2005; Travis et al., 2005; Strydom, 2009). The theoretical conclusion to this is that the criminal justice policy circumvents the psychological impact of family separation for the adults and the children.

\section{The Existing Incarceration and Rehabilitation Framework}

The Universal Declaration of Human Rights, The International Covenant on Economic, Social and Cultural Rights, and The United Nations Basic Principles for the Treatment of prisoners facilitate the route of rehabilitation to ensure that inmates are treated with care and dignity. South Africa is among countries that subscribe to these international conventions (Cilliers \& Smit, 2007; Singh, 2008). The Bill of Rights enshrined in chapter two of the Constitution of the Republic of South Africa of 1996 with reference to the detention system defines how the DCS should operate, which emulates international statutory measures with regard to the treatment of prisoners (Singh, 2008). The DCS (2005) has a provision of a detention system that is based on a Bill of Rights that provides the premise on handling incarcerated inmates (Cilliers \& Smit, 2007; Singh, 2008).

There has always been conflict between the punitive approach and the treatment (correctional) approach in the penal system (Zastrow, 2008; Strydom, 2009). The rehabilitation of the offender and the support of the victim, by way of a multidisciplinary approach and the presentation of a variety of programmes, should always be the main aim of incarceration in order to reintegrate the offender with society and the family so that they can once again function as a proper unit (Bezuidenhout, 2006; Cilliers \& Smit, 2007; Strydom, 2009). Rehabilitation is to bring about positive change in offenders and their fundamental behaviour. This is a primary requirement in order to affect this 
change that the offender should come to the realisation that his or her behaviour, deeds and actions were wrong.

The corrections are under the auspices of the Ministry of Correctional Services. The purpose of corrections in the criminal justice system is to punish, to rehabilitate, and to ensure public safety. However, corrections include probation, parole, and prison. The challenges faced by the DCS include Prison overcrowding; Corruption among department personnel; Failure to provide rehabilitative services to prisoners; HIV/Aids in prison among both staff and prisoners; and providing safe custody to juvenile prisoners. In the author's opinion, the provision of safe custody to juvenile prisoners is supposed to be the responsibility of the Ministry of Social Development. The challenge of overcrowding hampers the successful implementation of rehabilitation and development services.

\section{Conclusion}

It is a fact that families that have a member who is incarcerated, whether be a breadwinner or not, usually the family would struggle financially. The other point is that when the prisoner is released from prison either through parole (probationer) or after doing time, they usually recidivate due to unpreparedness for them to be re-united with the community. Cilliers \& Smit (2007) argue that if offenders still regard rehabilitation as a form of influencing the parole board, then it will never be a reality. The Corrections White Paper (2005) compatibly tries to address the issue of rehabilitation and re-entry of offenders to their communities including the importance of the family in the rehabilitation of offenders. Consequently, the rehabilitation of an incarcerated inmate with the exclusion of the family could be an incomplete process.

Literature proposes that a combination of family, community and societal conditions, especially poverty collude to trap offenders and their families into a cycle of crime (Cheliotis, 2008). The DCS currently has no assessment structure in place to identify the needs, readiness for treatment and personality traits of prisoners or the causes and motives behind crime. Consequently, the effective treatment of offenders cannot be ensured (Hasselink-Louw, 2003). Thus far, little or no attention has been focused on the working together of social services, criminal justice system, health care providers and communities to meet the needs of families left behind (Travis, et al, 2005).

\section{References}

Arditti, J.A., (2005). Families and incarceration: An ecological approach. Families in Society, 86(2), $251-260$.

Bezuidenhout, C. (2006). Increasing Detention and Incarceration Rates: Punitive Governments or Technological Advancements? Acta Criminologica: South African Journal of Criminology, 19(1): $57-76$. 
Braman, D. (2004). Doing time on the outside: Incarceration and family life in urban America. Ann Arbor: University of Michigan Press.

Cheliotis, L.K. (2008). Reconsidering the effectiveness of temporary release: A systematic review. Queen Mary: Aggression and Violent Behavior. 13: 153 168.

Christian, J., Mellow, J., \& Thomas, S. (2006). Social and economic implications of family connections to prisoners. Newark: Journal of Criminal Justice 34(1) 443 452.

Cilliers, C.H., \& Smit, J. (2007). Offender rehabilitation in the South African Correctional System: Myth or Reality? Acta Criminologica: South African Journal of Criminology, 20(2): $83-101$.

Department of Correctional Services, (2005). White Paper on Corrections in South Africa. Pretoria: Government Printers.

Diesel, A. \& Kollapen, J., (2002). Racism and Discrimination in the South African penal system. Braamfontein: Johannesburg Centre for the Study of Violence and Reconciliation.

Eddy, J. M., \& Poehlmann, J. (Eds.). (2010). Children of incarcerated parents: A handbook for researchers and practitioners. Washington, D.C.: Urban Institute Press.

Fishman, L.T. (1990). Women at the wall: A study of prisoner's wives doing time on the outside. Albany: State University of New York Press.

Freeman, R. (2003). Can We Close the Revolving Door?: Recidivism vs. Employment of Ex-Offenders in the U.S. New York University Law School, May 19 - 20, 2003.

Genty, P.M. (2002). Damage to Family Relationships as a Collateral Consequence of Parental Incarceration. Fordha Urban Law Journal, 30, (5), 1670 - 1684.

Gibson, C., Roberson, D., \& Daniel, A. (2009). African American Women on the Possibilities of a Relationship with an Ex-Offender. Kansas City, United States.

Hagan, J. \& Dinovitzer, R., (1999). Collateral Consequences of Imprisonment for Children, Communities, and Prisoners. Crime and Justice, 26, 121 - 162.

Hasselink-Louw, A., (2003). Criminological assessment of offenders: An analysis with the aim of promoting rehabilitation. Acta Criminologica: South African Journal of Criminology, 16(5).

International Centre for Prison Studies (ICPS) 2012 World in Brief. 2011.Viewed 12 April 2013 from http://www.prisonstudies.org/info/worldbrief/wpb_stats.php? Area=all\&category=wb_poptotal

Kennedy, J.E. \& Chance, M.W. (2011). Collateral Damage: How Mass Incarceration Increases Poverty and Crime in North Carolina's Poorest African American Communities. Trial Briefs, August 201115 - 16.

Mujuzi, J., (2008). The Prospect of Rehabilitation as a 'Substantial and Compelling' Circumstance to Avoid Imposing Life Imprisonment in South Africa: A Comment on S v Nkomo. SAJC.

Mumola, C.J. (2000). Incarcerated Parents and their Children. Washington, DC: Bureau of Justice Statistics.

Murray, J. (n.d.). The effects of imprisonment on families and children of prisoners.

Noble, M., Ratcliffe, A. \& Wright, G. (2004). Conceptualizing, Defining and Measuring Poverty in South Africa: An Argument for a Consensual Approach. Oxford: University of Oxford.

Nussbaum, M.C. (2000) Women and Human Development: The Capabilities Approach. Cambridge, Cambridge University Press. 
Pinard, M. (2010). Collateral Consequences of Criminal Convictions: Confronting Issues of Race and Dignity. New York University Law Review: May 2010, 85 $457-534$.

Republic of South Africa. (1996). Constitution of the Republic of South Africa, Act No. 108 of 1996. Pretoria: Government Printers.

Sen, A.K. (1979) Utilitarianism and Welfarism. The Journal of Philosophy: LXXVI (1979), $463-489$.

Sen, A.K. (1985). Commodities and Capabilities. Amsterdam: North-Holland.

Sen, A.K. (1993) Capability and Well-Being. The Quality of Life, pp. $30-53$. New York: Oxford Clarendon Express.

Sen, A.K. (1999). Development as Freedom. New Dehli: Oxford University Press.

Sen, A.K. (2009). The Idea of Justice. Cambridge, MA: The Belknap Press of Harvard University Press.

Sefara, M. (2002). Poverty, illiteracy in way of e-governance. The Star. 31 October:1

Seymour, C., \& Hairston, C.F. (2001). Children with Parents in Prison: Child Welfare Policy, Program and Practice Issues. New York: Transaction Publishers.

Singh, S. (2008). Towards Conceptual Clarity of Incarceration and Rehabilitation within the South African Criminal Justice System. Acta Criminologica: South African Journal of Criminology, SE(2): 59 - 77

Statistics South Africa, (2007). The Measurement of Poverty in South Africa Project: Key issues. Pretoria: Statistics South Africa.

Strydom, H. (2009). Psychological Needs of the Children of Incarcerated Parents. Acta Criminologica: South African Journal of Criminology, 22(2): 99 - 117.

Travis, J., \& Waul, M. (2003). Prisoners Once Removed: The Impact of Incarceration and Re-entry on Children, Families and Communities. Washington: The Urban Institute Press.

Travis, J., McBride, E.C., \& Solomon, A.L. (2005). Families left behind: The hidden costs of incarceration and re-entry. Washington: The Urban Institute Press.

costs of incarceration and re-entry. Washington: The Urban Institute Press.

United Nations Development Programme. (1990). Human Development Report. New York. Oxford University Press.

Williamson, G.R., (2005). Illustrating Triangulation in Mixed-Methods Nursing Research. Nurse Researcher, 12(4): 7 - 18.

World Bank, (2000). World Development Report 2000/2001: Attacking Poverty. Washington DC: World Bank.

World Summit for Social Development, (1995) Programme of Action of the World Summit for Social Development. Copenhagen: WSSD.

Zastrow, C. (2008). Introduction to social work and social welfare: empowering people. London: Thomson Brooks/Cole.

Zondi, C.Z., (2012). Community Participation in Community Correction Operation and Offender Re-Integration. International Journal for Cross-Disciplinary Subjects in Education, 3(3): 763 - 771 
